\title{
STUDY OF THE EFFECT OF EARLY FEEDING AFTER GUT RESECTION AND PRIMARY ANASTOMOSIS:A PROSPECTIVE RANDOMISED TRIAL
}

MN ZAMAN ${ }^{1}$, MMM PERVEZ $^{2}$, MAB AKAN $^{3}$, AM SHAHINOOR $^{4}$, M ANISUZZAMAN $^{5}$, MN ISLAM $^{6}$

\begin{abstract}
The traditional practice of post operative starvation after gut resection and primary anastomosis has been recently challenged. Contrary to wide spread opinion, evidence from clinical studies suggest that initiating feeding early is advantageous in postoperative patients. Various clinical trials have shown that early enteral feeding helps in the reduction of post operative ileus, anxiety and hospital stay. The purpose of this study was to compare the effects of early and traditional feeding, and was conducted among patients who underwent gut resection and primary end to end anastomosis.
\end{abstract}

The study population $(n=50)$ was divided into two arms. Arm-A ( $n=25)$ was given feeding after passage of flatus, stool when bowel sound was present, usually within second to fourth post operative day. Arm-B ( $n=25)$ was given early enteral feeding, started within 16-24 hours, in the first Post operative day (POD) after removal of the naso gastric tube.

There were no statistically significant variations in age, sex, bodyweight, average hemoglobin level, antibiotics, and suture materials used in both arms. Post operative hospital stay was 9.09 days in Arm-A

1. Dr. Md. Nooruzzaman ,Medical Officer, OSD, DGHS, Mohakhali, Dhaka,

2. Dr. MM. Masud Pervez Medical officer, urology,BIRDEM,Dhaka

3. Dr. Md. Abu Bakar Akan,Medical Officer, Upozila Health Complex,Swarupkhathi,Pirojpur

4. Dr. AM. Shahinoor, Medical Officer, Department of Paediatric Surgery, Bangabandhu Sheikh Mujib Medical University

5. Dr. Anisuzzaman,Registrar, Department of Surgery, Holy Family Red Crescent Hospital, Dhaka

6. Dr. Md.Nazrul Islam, Medical Officer, Department of Paediatric Surgery, Bangabandhu Sheikh Mujib Medical University

Correspondence to: Dr. Md Nooruzzaman, Medical Officer, OSD, DGHS, Mohakhali, Dhaka, E-mail: mnzamandj3@gmail.com and 5.42 days in Arm-B. It was significantly low ( $P<$ 0.05 ) in Arm-B. The complications after operation were also low in Arm-B. Early enteral feeding can help to decrease the negative impact of the metabolic response to injury. It also stimulates restoration of the barrier functions of the intestine, improve the return of the functions and reduce the duration of post operative ileus and hence reduce the risk of serious complications.

Key words: Early enteral feeding, post operative day, traditional feeding.

\section{Introduction}

The traditional practice of postoperative starvation after abdominal surgery recently has been challenged. Early enteral feeding has been shown by various clinical trials as having benefits in reduction of post operative ileus and hospital stay. ${ }^{1}$

Contrary to wide spread opinion evidence from clinical studies suggest that initiating feeding early is advantageous in postoperative patients.

Post operative dysmotility pre dominantly affects the stomach and colon. With the small bowel recovering normal function 4-8 hours after laparotomy feeding within 24 hours after laparotomy is tolerated and the feed is absorbed. ${ }^{2}$ On the other hand enteral nutrition is physiologic and has been shown to be more cost effective without the added risk of nosocomial infection inherent in parenteral nutrition. ${ }^{2}$

In recent years, several studies showed that early feeding after elective open colectomy was safe and tolerated by the majority of patients. ${ }^{3}$ 
A potential benefit of early oral feeding in open abdominal surgery would be a reduced hospital stay, leading to a reduction in hospital cost. ${ }^{4}$

In the laboratory it has been shown that starvation reduces the collagen content in anastomotic scar tissue in animals which diminishes the quality of healing. Feeding reduces the mucosal atrophy induced by starvation and increases anastomotic collagen deposition and strength. Experimental data in both animals and human suggest that early enteral nutrition is associated with an improvement in wound healing. ${ }^{5}$

Early feeding reduced the post operative complications. So early oral feeding improved the nutritional status of the patients which helped them to heal the wound properly.

\section{Materials and Methods}

It is a prospective comparative study between traditional feeding Arm-A, $n-25$ and early feeding ArmB, n-25.

Study was conducted in patients with gastro intestinal disorder who need resection \&primary end to end anastomosis).

Method of sampling

Inclusion criteria

Paients undergone resection and primary end to end anastomosis of gastro intestinal tract.

\section{Exclusion criteria}

Malnourished patients

Immunocompromised patients
Diabetic patients

Patients not consenting to the protocol

\section{Data collection}

Informed consent was taken from the patients and the legal guardians of the patients. Data was collected in predesigned data collection sheet by taking history and examination and relevant investigation.

\section{Protocol of Feeding}

1. Arm-A- Feeding was started when the patient has passed flatus, bowel has moved or bowel sound was present, usually within $2^{\text {nd }}$ to $4^{\text {th }}$ postoperative day, after removal of Nasogastric tube. Both volume and frequency of feed were inconsistent.

2. Arm-B-Enteral feeding was started within 24 hours after removal of nasogastric tube in the $1^{\text {st }}$ postoperative day. First feeding started with $10-50 \mathrm{ml}$ of clean water followed by ORS, glucose water and liquid diet given at 4 hours interval. Initial volume was increased every feed up to the daily maintenance volume. When patients were able to tolerate at least $80 \%$ of daily maintenance volume then normal diet was given on $2^{\text {nd }} P O D$. Post operative complications were noted after every feed. Patients were followed up at $14^{\text {th }}$ P.O.D and one month thereafter in most cases.

\section{Results}

Table-I

Comparison of the demo graphic data between two groups

\begin{tabular}{llcccc}
\hline Navigable & & $\begin{array}{c}\text { Tradition } \\
\text { feeding Arm-A } \\
(\mathrm{n}-25)\end{array}$ & $\begin{array}{c}\text { Early feeding } \\
\text { Arm-B } \\
(\mathrm{n}-25)\end{array}$ & $\begin{array}{c}\text { P-value } \\
<0.05\end{array}$ & Comment \\
\hline Anasto motic site & Small gut & $15(63.6 \%)$ & $14(57.1 \%)$ & 0.74 & Not significant \\
& Large gut & $10(36.4 \%)$ & $11(42.9 \%)$ & 0.74 & Not significant \\
& Average haemo & 11.06 & 10.51 & 0.11 & Not significant \\
& goblin gm / dl & & & & \\
\hline
\end{tabular}

\section{Day of Nasogastric tube omitted}

In case of Arm-B (early enteral feeding) naso gastric tube was removed on $1^{\text {st }} P O D$ in all cases. But in Arm-A (traditional feeding) nasogastric tube was removed between $2^{\text {nd }}$ to $4^{\text {th }}$ P.O.D. 


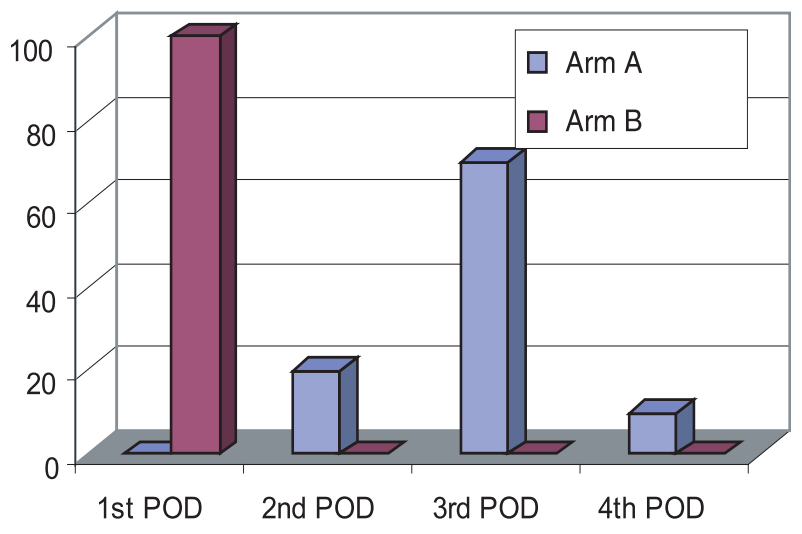

Fig.-1 Day of Naso gastric tube removed
Table- II

Comparison of post operative complication between two groups.

\begin{tabular}{lcc}
\hline Complication & Arm-A (n-25) & Arm-B (n-25) \\
\hline Vomiting & 1 & 1 \\
Diarrhea & 4 & 0 \\
Wound disruption & 0 & 0 \\
Gl bleeding & 2 & 0 \\
Nausea & 7 & 2 \\
UR TI & 6 & 0 \\
Unspecified fever more & 3 & 0 \\
than 48 hours & & \\
\hline
\end{tabular}

Table-III

Post operative Hospital Stay

\begin{tabular}{llllcccr}
\hline Arm & $\mathrm{n}$ & Minimum & maximum & Mean & S.D & P.Value & Comment \\
\hline A & 25 & 6 days & 17 days & 9.09 & \pm 3.24 & 0.002 & Significant \\
B & 25 & 4 days & 9 days & 5.28 & \pm 1.53 & & \\
\hline
\end{tabular}

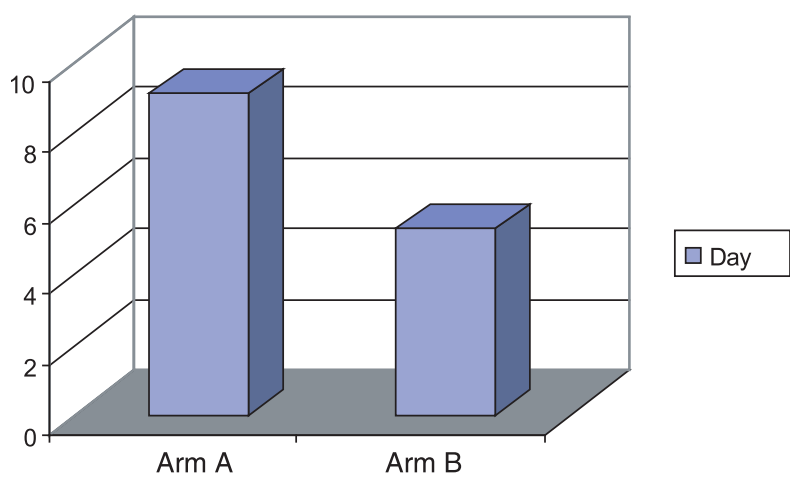

Fig.-2: Mean postoperative hospital stay .

\section{Discussion}

After abdominal surgery it is generally agreed that there is certain period that peristalsis of intestine halts or is less well organized. This so called paralytic ileus varies according to the extent of operation, type of anesthesia and abdominal pathology. Besides clinical signs there is no objective way to evaluate adequacy of peristalsis. Postoperative enteral feeding then is traditionally started when there is less abdominal distention and patient passes flatus or defecates. ${ }^{6}$

However, post operative starvation has been challenged. Randomized trials in adult lower GIT surgery showed benefit of early enteral feeding in terms of reduction in length of stay and post operative complication. ${ }^{7,8}$
In this study there were no significant differences $(P=0.11)$ between the two age groups. Both groups were matched for bodyweight, haemoglobin level, operation time, and blood transfusion.

Nasogastric tube was introduced in all patients either before or during operation. In case of early enteral feeding nasogastric tubes were omitted on $1^{\text {st }}$ P.O.D in all cases. But in traditional feeding they were omitted from $2^{\text {nd }}$ to $4^{\text {th }}$ P.O.D. In studies by Zong Zhoo et al, naso gastric tubes were removed within 12 to 24 hours after operation in early feeding group. In control group (late feeding group) nasogastric tubes were removed upon report of passage of flatus by patients, usually within 3 to 5 days after surgery ${ }^{8}$. Early elimination of post operative nasogastric tube decreases post operative fever ${ }^{9}$, pulmonary problems and improves patients' comfort by decreasing sore throat and nausea 10. Delayed omission of post operative nasogastric tube could increase post operative complications such as fever sore throat and pulmonary problems. ${ }^{89}$

Regarding anastomotic site in Arm-A, 14 patients (63.61\%) had small intestine, and 8 had $(36.41 \%)$ large intestine. On the other hand in Arm-B 16 patients $(57.11 \%)$ had small gut and 12 patient $(42.91 \%)$ had large gut, which is statistically not significant $(p>0.05)$.

The length of hospitalization in early feeding group was significantly shorter than in late feeding group (7 
days and 10 days $)^{6}$. But in our study the average post operative hospital stay were 9.09 days (range 8 days to 17 days) in Arm-A and 5.28 days (range 5 days to 9 days) in Arm-B. Unpaired (t) test showed statistically significant difference ( $p$ value 0.002 ) in post operative hospital stay in Arm-A and Arm-B.

The complications observed in Arm-A were vomiting, Diarrhea (4 patients), URTI (6 patients) and lower GI bleeding (2 patients). In Arm-B no patient had URTI. It might be due to nosocomial infection due to negative impact of metabolic response to surgery. The G.I bleeding might be due to post operative reactionary hemorrhage.

Post operative complications such as fever $(3.73 \%$ vs. $9.68 \% p<0.05)$ pulmonary infection $(0.62 \%$ vs $4.52 \% \mathrm{P}<0.05)$ were much more in control group than in experimental group ${ }^{7} .104$ patients who underwent colorectal surgery including closure of colostomy oral diet was given in 89 patients on $1^{\text {st }}$ or $2^{\text {nd }}$ P.O.D. 65 patents $(73 \%)$ tolerated early feeding. Of 24 patients that did not, 16 had nausea or emesis and 8 required readmission for post operative complications (such as wound dehiscence and anastomotic leak). Univariate analysis revealed that the use of volume expanders contributed to intolerance of early feeding ${ }^{12}$. In late feeding negative impact of metabolic response to surgery may increase the post operative complications. ${ }^{13}$ Prolong staying in hospital after operation also increase the nosocomial infection. (U.R.T.I, Diarrhea etc.) Positive psychological impact of feeding after surgery may have an important role in recovery process. ${ }^{13}$

On the contrary early enteral feeding can help to improve energy and protein intake, and decrease the negative impact of the metabolic response to injury. It also stimulates motor restoration, Synthetic and barrier functions of the small intestine improve the return of GIT functions and reduce the duration of operative management and reduce the risk of serious complications.

Early feeding in post operative patients is a new concept to us. Our nursing staff and doctor ratio is less. Most of the patients being illiterate cannot follow the feeding protocol. So patients need frequent follow up to observe the side effects of early feeding such as vomiting, abdominal distention, fever etc. So, more time needs to be spent to follow up the patients to overcome these problems.

\section{Conclusion}

From present study it could be concluded that early removal of nasogastric tube and early oral feeding in the patients who have under gone resection and primary end to end anastomosis is feasible and safe. It can reduce the post operative complications and discomfort. It could also decrease the length of post operative hospital stay which reduces the morbidity of the patients. Thus early oral feeding may become a routine protocol of management after resection and primary end to end anastomosis.

\section{References}

1. Levis Sy. Egger M. Syl. Sy Egger M. Syl. vester PA et al. Early enteral feeding versus nil mouth after gastro intestinal surgery. Systems review and meta -analysis of controlled trials. BMJ . 2007, Vol-323, pp 773-76.

2. Sufasak sangkha that. Sakda patra pinyokul and kamol nate Tadya thikon et al early enteral feeding after closure of colostomy. Journ-of surg,2003, vol. 38,pp.1516-19

3. Akira Tsunoda, M. Shibusawa, M. Takata el “ Early oral feeding should be resumed following the resolution of grastric illeus" Hepatogastroenterology 2005 Vol-52,pp-775-79

4. Cornelia S carr K.D Eddie ling paul Boulos et al Rando mised trail of safety and efficacy of immediate post operative enteral feeding in patients under going gastrointes tinal resection" Bmj 1996, Vol-312, pp. 869-71.

5. E.E. Moore Todd N. Yones "Benefits of immediate Jejunos tony feeding after major abdoninal trauma. A prospective Ramdonized study" Journal of Trauma 1986, vol-26. pp- 874-79.

6. F.A. moore DV feliciano R.J Andrally et al, early enteral feeding compared with parenteral vdeduces post operative septic. Complications" Ann surgery 1992, Vol-216, pp-172-83

7. L. Andrew Di Fronzo, Ju8dith eymesman, Theodore X o'connel et al Factors affecting early postoperative feeding following elective colon resection, Arch surgery 1999, Vol-134, pp-94146.

8. Nicholas J Petrelli, chasler chang. Deborah Dricoll et al " Early postoperative oral feeding after colectony " an analysis of factors that may predict 
faulure. Journals of surgical oncology 2001, Vol8 (10).pp.796-800.

9. P Allen Hartsel R.C Frazee J.B Harrison el al “ Early postoperative Feeding after elective colorectal surery Arch surgery 1997, Vol 132 pp.518-21.

10. Tong Zhou xiao- Ting wu. yejiang Zhoo et al early removig lastrointestinal decompression. X early oral feeding improve patients rehabilitation after colorecto stomy. World j lastro enterol . 2006, Vol-12 pp.2459-63.
11. Menzies D post operative complication: their tretment and relevance in clinical practice. An 2 R coll surg engl1993, vol 75. Pp.147-53.

12. T. okabayashi M kobayashi gsao Nishimori et al Benelits of early postoperative et al. Benefits of early postoperative Jejunal feeding in patients Undergoing duodeno hemi pancreatec tomy. World J. lastro enter 2006. Vol-712 (1)pp. 83-93.

13. Petachia Reissman T-Ann Teoh stephen M. coen et al. Is early oral feeding saye after elective colorectal surgery. Annals of surger 2003, Vol222, pp.73-77. 